\title{
Article \\ Characterising Correlations between Electric Conductivity and Structural Features in Rotary Swaged A1/Cu Laminated Conductors
}

\author{
Lenka Kunčická $^{1}$, Radim Kocich ${ }^{2, *}$, Petr Kačor ${ }^{3}$,, Michal Jambor $^{1}\left[\right.$ and Martin Marek ${ }^{4}$ \\ 1 Institute of Physics of Materials, Czech Academy of Sciences, Žižkova 22, 61600 Brno, Czech Republic; \\ kuncicka@ipm.cz (L.K.); jambor@ipm.cz (M.J.) \\ 2 Faculty of Materials Science and Technology, VŠB-Technical University of Ostrava, \\ 70800 Ostrava-Poruba, Czech Republic \\ 3 Department of Electrical Power Engineering, VŠB-TU Ostrava, 17. listopadu 2172/15, \\ 70800 Ostrava-Poruba, Czech Republic; petr.kacor@vsb.cz \\ 4 Department of Technical Studies, College of Polytechnics Jihlava, Tolsteho 16, 58601 Jihlava, Czech Republic; \\ martin.marek@vsb.cz \\ * Correspondence: radim.kocich@vsb.cz; Tel.: +420-596-994-455
}

Citation: Kunčická, L.; Kocich, R.; Kačor, P.; Jambor, M.; Marek, M Characterising Correlations between Electric Conductivity and Structural Features in Rotary Swaged $\mathrm{Al} / \mathrm{Cu}$ Laminated Conductors. Materials 2022, 15, 1003. https://doi.org/ $10.3390 / \mathrm{ma} 15031003$

Academic Editor: Andres Sotelo

Received: 25 December 2021

Accepted: 26 January 2022

Published: 27 January 2022

Publisher's Note: MDPI stays neutral with regard to jurisdictional claims in published maps and institutional affiliations.

Copyright: (C) 2022 by the authors Licensee MDPI, Basel, Switzerland. This article is an open access article distributed under the terms and conditions of the Creative Commons Attribution (CC BY) license (https:// creativecommons.org/licenses/by/ $4.0 /)$.

\begin{abstract}
This study aims to characterize the correlations between electric characteristics and selected structural features of newly designed $\mathrm{Al} / \mathrm{Cu}$ laminated conductors manufactured via room temperature rotary swaging. After swaging, the laminates with diameters of $15 \mathrm{~mm}$ were subjected to two different post-process annealing treatments. Structure analyses performed to evaluate the effects of thermomechanical processing were performed via scanning and transmission electron microscopies. Electric conductivity and resistivity of the laminates were experimentally measured and numerically simulated using models designed according to the real conditions. The results showed that the electric resistivity was affected by the grain size, bimodal grains' distribution (where observed), the presence of twins, and, last but not least, dislocation density. Among the influencing factors were the area fractions of $\mathrm{Al}$ and $\mathrm{Cu}$ at the cross-sections of the of the laminated conductors, too. The results revealed that fabrication of the laminate via the technology of rotary swaging introduced more advantageous combinations of electric and mechanical properties than fabrication by conventional manufacturing techniques. The lowest specific electric resistivity of $20.6 \Omega \mathrm{m} \times 10^{-9}$ was measured for the laminated conductor subjected to the post-process annealing treatment at $350{ }^{\circ} \mathrm{C}$, which imparted significant structure restoration (confirmed by the presence of fine, equiaxed, randomly oriented grains).
\end{abstract}

Keywords: rotary swaging; aluminium; copper; composite; microstructure; electric properties

\section{Introduction}

Generally, laminates are structures consisting of more than one material (element, alloy), and can be fabricated in various forms (layers, imposed fibres, wires, fibres embedded in resin, etc.). Metallic laminates, which can also be denoted as bimetallic composite materials, are popular modern industrial materials and can find their use e.g., in automotive, aerospace, and marine fields [1,2]. The fact that each of the components introduces specific advantageous properties enhances the performance of the final product.

Not only the design of the laminate, i.e., the selection of component metals and their localization, but also the production method and selected processing temperatures non-negligibly influence the final properties. Metallic laminates can be manufactured by methods (locally) introducing elevated temperatures, such as various types of welding and cladding [3-7]. However, such methods disadvantageously affect structures of the metallic components and promote the formation of brittle intermetallics. For this reason, the 
fabrication of metallic laminates via methods of intensive (and severe) plastic deformation, which can advantageously be performed at room temperature, is promising.

The methods of plastic deformation are based on imposing (high) shear strain into the processed materials, which enables metallurgical bonding of the individual composite components. Generally, the higher the amount of the imposed strain, the better the bonding quality. For this reason, the methods of severe plastic deformation (SPD), especially equal channel angular pressing (ECAP) [8-10] and related methods (twist channel angular pressing-TCAP [11], twist channel multi angular pressing-TCMAP [12], equal channel angular pressing-Conform-ECAP-Conform [13], equal channel angular pressing with partial back pressure-ECAP-PBP [14], etc.) can be considered to be very favourable. However, the majority of SPD methods are designed to process very small bulk samples. Laminates can also be produced by conventional forming methods (such as rolling, forging, drawing, and extrusion), but the amount of shear strain that can possibly be introduced by conventional methods is limited. Rotary swaging (RS) is a method of intensive plastic deformation, by which a high amount of shear strain can advantageously be imposed. Therefore, RS is a favourable method for the production of complex composites [15]. Among other advantages of RS is the dominating compressive stress state supporting metallic bonding of the individual layers [16], and its versatility (it can be used to process long axisymmetrical products-rods and wires [17]). The applied processing conditions, such as the deformation ratio, stress state, and amount of imposed strain, affect the deformation behaviour of the laminate (formation of slip or kink bands, etc.), preferential deformation mechanisms (dislocation slip, dislocation climb, twinning, etc.), structure modifications (subgrains' formation, texture orientations, grain size, etc.), and consequently also the mechanical, physical, electrical, and utility properties [18]. For example, inhomogeneous stress distribution, i.e., inhomogeneous distribution of residual stress, not only contributes to decreased quality or longevity of components' bonding, but also deteriorates other properties, e.g., electric conductivity $[19,20]$. Nevertheless, the majority of the mentioned parameters can be optimized during processing.

Laminates typically consist of two ( $\mathrm{Al}$ and $\mathrm{Mg}$ [21], $\mathrm{Al}$ and $\mathrm{Ni}$ [22], $\mathrm{Al}$ and $\mathrm{Sn}$ [23], $\mathrm{Cu}$ and $\mathrm{Ni}$ [24], $\mathrm{Cu}$ and $\mathrm{Ti}$ [25], etc.) or more ( $\mathrm{Cu}$ and $\mathrm{Al}$ and $\mathrm{Zn}$ [26], $\mathrm{Cu}$ and $\mathrm{Al}$ and $\mathrm{Mg}$ [27], $\mathrm{Cu}$ and $\mathrm{Al}$ and steel [28], $\mathrm{Al}$ and $\mathrm{Cu}$ and $\mathrm{Zn}$ and $\mathrm{Ni}$ [29]) metallic materials (elements). Nevertheless, the most commonly researched and fabricated are materials consisting of combinations of $\mathrm{Al}$ and $\mathrm{Cu}$. These two metals are popular components for laminated conductors, of which various designs and stacking sequences have been researched e.g., [3,15,18,21,25]. Laminates consisting of $\mathrm{Al}$ and $\mathrm{Cu}$ feature advantageous thermal and electric conductivity, favourable corrosion resistance, and lighter weight and lower cost when compared to (commercially) pure $\mathrm{Cu}$ [30]. $\mathrm{Al} / \mathrm{Cu}$ composites are prone to form hard and brittle intermetallic phases at mutual interfaces. However, methods of plastic deformation performed at optimized processing conditions enable successful room temperature fabrication of $\mathrm{Al} / \mathrm{Cu}$ laminates. Room temperature processing is also favourable from another viewpoint: During processing at elevated temperatures, both the $\mathrm{Al}$ and $\mathrm{Cu}$ are highly prone to dissolve oxygen. Dissolved oxygen significantly deteriorates the electric conductivity of $\mathrm{Cu}$. Moreover, the presence of $\mathrm{Cu}_{2} \mathrm{O}$ precipitates in the structure substantially reduces plasticity and durability and can result in the formation of bubbles and subsequent cracking when in contact with hydrogen (i.e., water) [31].

Although works dealing with the fabrication of $\mathrm{Al} / \mathrm{Cu}$ laminates via methods of plastic deformation have been published before, studies reporting the effects of processing procedures on interactions of (sub)structures and electric properties are scarce. Prospective applications of the presented laminated conductors are e.g., in the manufacture of rotors of asynchronous machines. The existing manufacturing technology of rotor windings involves (vacuum) die-casting, which introduces defects significantly deteriorating the overall quality of the windings (e.g., air bubbles, entrails, coagulants). For high-efficiency machines, the contemporary tendency is to shift from $\mathrm{Al}$ windings to $\mathrm{Cu}$ cages. However, the casting of $\mathrm{Cu}$ is a complex process performed at high temperatures, which can deterio- 
rate its electrically insulating properties. Room-temperature fabrication of $\mathrm{Al} / \mathrm{Cu}$ or $\mathrm{Cu} / \mathrm{Al}$ composite conductors of the required final dimensions, which can be used directly for rotor bar windings of asynchronous machines, via swaging is thus very promising.

The presented work aimed to characterize the correlation between structure characteristics and electric behaviour for a uniquely designed $\mathrm{Al} / \mathrm{Cu}$ laminated composite. The laminate was fabricated via room-temperature rotary swaging, and subsequently subjected to two different heat treatments. Before fabricating an electric conductor, it is favourable to determine the type of current that will be used during its testing and usage. In other words, will the conductor be used to transfer alternate or direct current (the transfer efficiency is affected by the occurrence of skin effect for alternate current)? The herein presented $\mathrm{Al} / \mathrm{Cu}$ laminate is considered to be applicable for the transfer of both direct and alternate electric currents. However, the main focus of this study was to characterize the electric behaviour of the laminate during direct current transfer. The electric characteristics were measured on the experimentally swaged (and heat treated) laminated rods, and also numerically simulated. Structure analyses were performed via scanning and transmission electron microscopies. Microhardness measurements were performed to supplement the structure observations.

\section{Materials and Methods}

\subsection{Experiment}

The materials used to produce the laminates were electro-conductive commercially pure $(\mathrm{CP}) \mathrm{Cu}(\mathrm{Cu}$ and $0.015 \% \mathrm{P}, 0.002 \% \mathrm{Zn}, 0.002 \% \mathrm{O})$, and electro-conductive $\mathrm{CP} \mathrm{Al}$ ( $\mathrm{Al}$ and $0.25 \% \mathrm{Fe}, 0.21 \% \mathrm{Si}, 0.04 \% \mathrm{Cu}$ ). The laminates were prepared by rotary swaging at room temperature $\left(\sim 23{ }^{\circ} \mathrm{C}\right)$. The unique stacking sequence of the $\mathrm{Al} / \mathrm{Cu}$ laminate was designed based on our previous experience: The peripheral and axial regions of the laminate should consist of $\mathrm{Cu}$, while the remaining volume of the laminate should consist of $\mathrm{Al}[32,33]$. The $\mathrm{Cu}$ lamellas were located in a stellulate pattern within the Al matrix (the laminated workpiece is shown in the photo in Figure 1a). The diameter of the original composite workpiece, which was finally swaged down to the diameter of $15 \mathrm{~mm}$, was $50 \mathrm{~mm}$ (the swaged laminated composite is shown in the photo in Figure 1b). The length of the original workpiece was $150 \mathrm{~mm}$. The final reduction ratio for the laminate, calculated using Equation (1), was 2.4:

$$
\varphi=\ln \left(\frac{S_{0}}{S_{n}}\right)
$$

where $S_{0}$ and $S_{n}$ are laminate cross-section areas at the input and output from swaging dies, respectively.

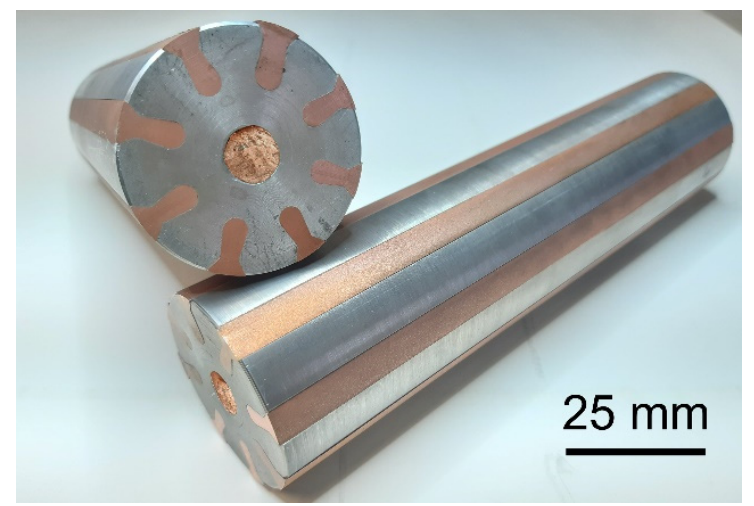

(a)

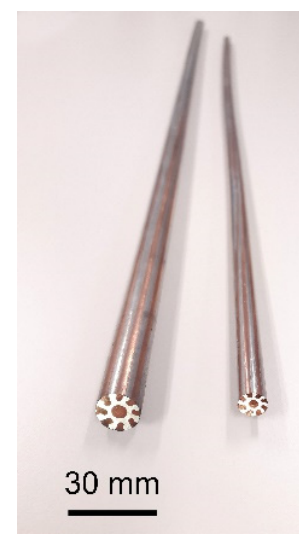

(b)

Figure 1. $\mathrm{Al} / \mathrm{Cu}$ laminated workpiece (50 mm diameter) (a); swaged laminate (15 mm diameter) (b).

The swaged products were further subjected to two annealing regimes to characterize the effects of post-process heat treatments on their structures and electric characteristics. 
The first regime was carried out at the temperature of $250{ }^{\circ} \mathrm{C}$ (regime HT1), and the second one was performed at the temperature of $350{ }^{\circ} \mathrm{C}$ (regime HT2). The post-process annealing treatments were selected considering the data acquired during our previous researchwhen subjected to post-process annealing, structures of the swaged laminates exhibited the tendency to recover. Nevertheless, annealing at temperatures higher than $350{ }^{\circ} \mathrm{C}$ imparted grain growth and the formation of intermetallics [34]. For each of the heat treatment regimes, the electric furnace was heated to the required temperature. Then, the laminate was inserted into the heated furnace for a dwell time of $15 \mathrm{~min}$. After the time dwell, the laminate was taken out of the furnace and cooled freely on air.

Subsequently, the electric characteristics of all the swaged and heat-treated laminates were measured. Electric resistivity of the rods was detected experimentally using the highly accurate Four-Wire Resistance Measurements method. During the measurements by this method, two pairs of electrodes were used: Sense probes, which measured the voltage drop on the determined length of the laminate, and source probes, which supplied current to the measured laminate [35]. The use of two pairs of separate electrodes ensured that no supply current passed through the sensing electrodes, and that the sensing electrodes measured the voltage drop $V_{1}$ only. The source probes were connected in series with a calibrated shunt resistor to provide an accurate current measurement; the values of the current supplied by the used source were between 0 and $100 \mathrm{~A}$. The voltage drop $V_{2}$ monitored by the shunt resistor was directly related to the applied electric current via the $K=0.0004 \Omega$ constant. Therefore, the current value could be characterized by the relation $I_{1}=V_{2} / K$. The sense probes monitoring the voltage drop $V_{1}$ during current flow were fixed on the measured laminate with the mutual distance $d L=500 \mathrm{~mm}$. By using Ohm's law, Rs (electric resistivity of the swaged laminate) on the measured length $L(500 \mathrm{~mm})$ was further computed by dividing the voltage drop $V_{1}$ and electric current $I_{1}$ as $R s=V_{1} / I_{1}$.

Measurements of electric resistivity $R s$ of the swaged laminated rods should be carried out quickly since the conductors exhibit the tendency to heat by the effect of current flow. During the measurements, the current value increased rapidly from $0 \mathrm{~A}$ to $100 \mathrm{~A}$, and then dropped again to $0 \mathrm{~A}$. For such rapid changes, manual data recording was not possible. For this reason, both the voltage drops $V_{1}$ and $V_{2}$ were detected synchronously using a DAQ (Data AcQuisition) card (NI-9238 type) and stored in a data file. The DAQ card had a 24-bit resolution at the voltage range of $\pm 500 \mathrm{mV}$. This enabled us to achieve the minimum measurable sensitivity $d U=60 \mathrm{nV}$. The stored data then provided the basis for the calculation of specific electric resistivity $\rho$ via Equation (2),

$$
\rho=R \cdot \frac{S}{L}=\frac{V_{1}}{I_{1}} \cdot \frac{S}{L}=\frac{V_{1}}{I_{1}} \cdot C
$$

where $R$ is the resistivity [ $\Omega$ ], $S$ is the cross-sectional area of swaged laminate $\left[\mathrm{m}^{2}\right], V_{1}$ is the voltage drop [V], $I_{1}$ is the DC current supply [A], $L$ is the measured length between the voltage sensors of the swaged laminate [m], and $C$ is the constant for the characteristic dimension $[\mathrm{m}]$.

Before measuring the electric characteristics of the laminated composite rods, the data for the original $\mathrm{Al}$ and $\mathrm{Cu}$ materials were acquired. Figure 2 depicts the dependence of the voltage drop $V_{1}$ on the electric current for the original $\mathrm{Al}$ and $\mathrm{Cu}$ laminate components. The measured values were smoothed by a linear fit for both metals. The slopes of the curves $\left(V_{1} / I_{1}\right)$ determine the resistivity $R$ of the measured metals per $1 \mathrm{~m}$ of length. 


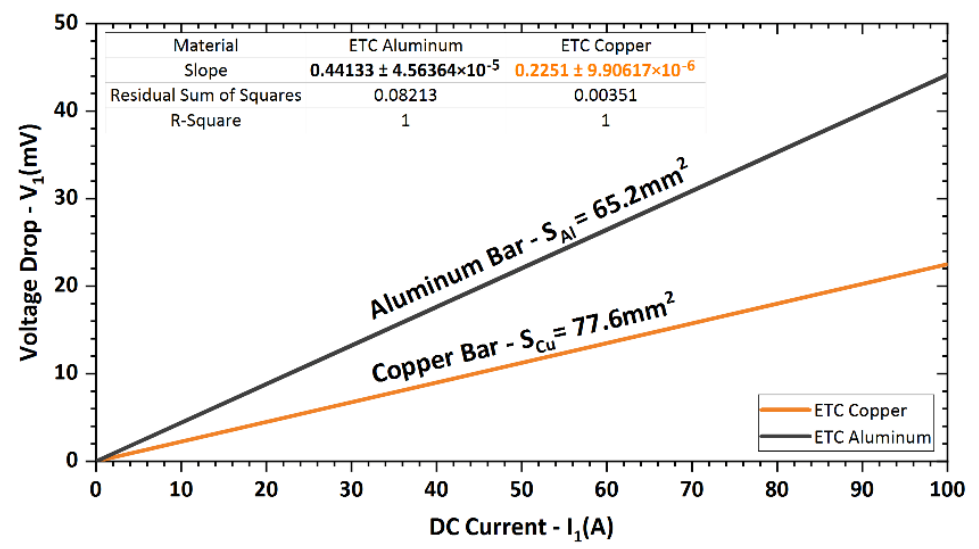

Figure 2. Measured voltage drop $V_{1}$ in dependence on applied current $I_{1}$ for original metals.

Structure analyses of the swaged (and heat treated) laminated rods were carried out by scanning and transmission electron microscopies (SEM and TEM). The samples for SEM electron backscatter diffraction (EBSD) observations, prepared from transversal cuts, were grinded manually, polished electrolytically, and observed using a Tescan Lyra 3 XMU FEG/SEMxFIB device equipped with a Symmetry EBSD detector (Tescan, Brno, Czech Republic). The analyses were carried out with the step of $0.5 \mu \mathrm{m}$ on samples tilted by $70^{\circ}$ and evaluated with the help of Aztec Crystal software (Oxford Instruments, Abingdon, UK). Detailed analyses of substructures of the $\mathrm{Cu}$ lamellas from the swaged and heat-treated laminates were performed using TEM (JEOL JEM-2100 device, JEOL, Tokio, Japan). The observations were performed at $200 \mathrm{kV}$ on samples prepared using the focused ion beam (FIB) method assembled on the Tescan Lyra 3 XMU microscope. During FIB preparation, a lamella was milled with Ga ions in multiple steps to a final thickness of about $120 \mathrm{~nm}$. The FIB lamella was taken from a transversal cut through a peripheral $\mathrm{Cu}$ lamella, and thus the TEM observations were carried out in a direction parallel to the swaging axis. The last experimental step involved Vickers microhardness measurements, which were performed using a Zwick/Roell testing device (Zwick Roell CZ s.r.o., Brno, Czech Republic). For each indent, the load was $200 \mathrm{gf}$, and the loading time was $10 \mathrm{~s}$.

\subsection{Numerical Analysis}

To supplement the results of experimental investigations, numerical simulations of the current transfer were performed for the swaged laminated rods with diameters of $20 \mathrm{~mm}, 15 \mathrm{~mm}$, and $10 \mathrm{~mm}$. The geometries of the swaged rods models ensued from the experimentally observed ones. In other words, the locations and deformations of the individual composite components of the modelled rods were based on the locations and deformations of the $\mathrm{Al} / \mathrm{Cu}$ laminate components observed experimentally via SEM.

Figure 3 depicts a model of the laminated rod with individual modelling components (introduced for simulation purposes) depicted with the letters $A, B$, and $C$, and the cross-section of a laminated rod corresponding to the real laminate swaged to the diameter of $15 \mathrm{~mm}$. The model of the laminated rod consisted of three individual modelling components:

- Components $A$-auxiliary components serving as the input and output of the electric current. The terminal cylindrical material volumes served to stabilize the current lines occurring by the effect of current transfer and represented the total current $I=100 \mathrm{~A}$. In the numerical model, these terminal volumes were defined as conductors with negligible electric conductivity.

- Components $B$-represented the operational part of the laminated conductor. They enabled homogeneous transformation of the computational elements in the model and provided the smooth attachment of the central part of the laminate. 
- Components $C$-Represented the significant (i.e., central) part of the laminate, on which evaluation of the output parameters was performed. The basic parameters were the distribution of the current density across the cross-section of the swaged laminate, and the power loss occurring due to the flowing current.
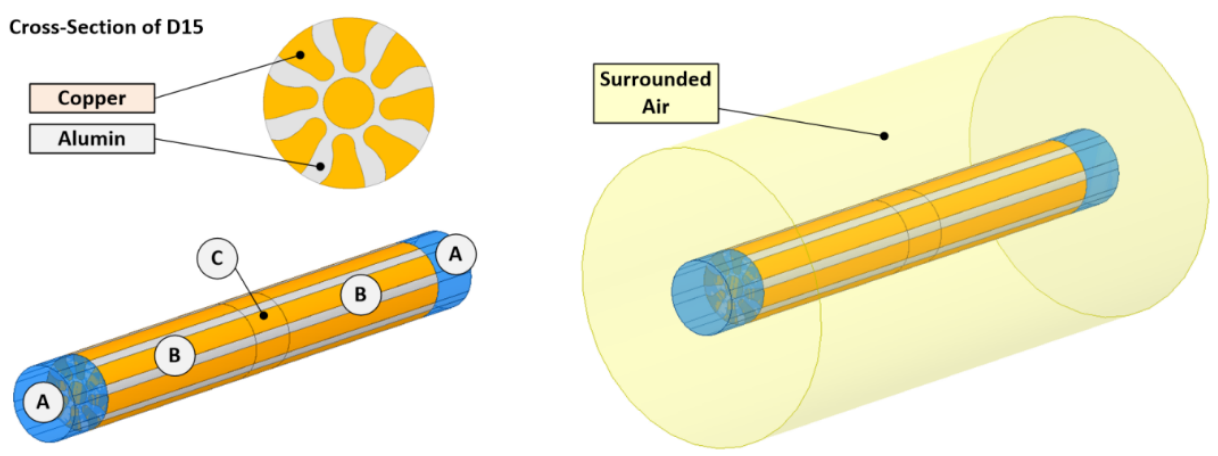

Figure 3. Model of laminated rod with individual components.

The electromagnetic model of the laminated conductor was used to perform a harmonic electromagnetic analysis using Ansys Electronic Desktop software. A harmonic electromagnetic simulation enabled us to determine the value of power loss $\mathrm{dP}(\mathrm{W})$ when the value of the current in the conductor was known. The value of the current used in the simulation, as well as during the experiments, was $I=100$ A. After determining the values of transferring current (input parameter) and power loss (output parameter), the calculation of the total value of electric resistance of the laminated conductor was performed via Equations (3) and (4),

$$
\begin{gathered}
d P=\frac{1}{\sigma} \int_{\text {vol }} J^{2} d V \\
R=\frac{d P}{I^{2}}
\end{gathered}
$$

where $d P$ is the current loss $(\mathrm{W}), \sigma$ is the electric conductivity of the material from which the conductor is fabricated $\left(\mathrm{Sm}^{-1}\right), J$ is the current density $\left(\mathrm{A} / \mathrm{m}^{2}\right), d V$ is the element of the conductor volume $\left(\mathrm{m}^{3}\right), R$ is the resistance of the conductor $(\Omega)$, and $I$ is the value of the supply current.

To determine the final value of electric resistance of the laminated rod, the basic equation for the calculation of the total resistance of net resistances in series and parallel circuits (see Figure 4) was used.
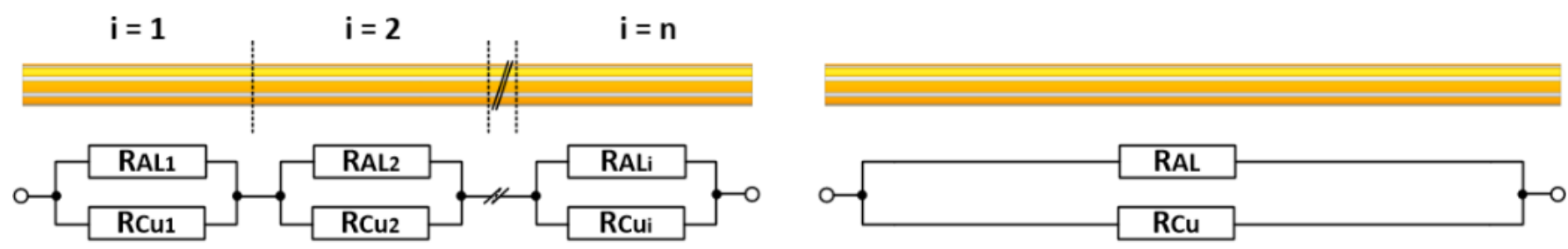

Figure 4. Schematic depiction of series and parallel circuits.

The parallel resistance parts, RAli | | RCui, represented the length portion of the laminated conductor selected for the elements $i$. In the elements (nodes) $i$ of the conductor, the ideal mutual connection between the laminate components was considered. The final resistance of the entire length of the conductor then consisted of the sum of resistances for the elements $i$, which represented the parallel combination of $n$ resistances determined by the cross-section of the conductor, and specific electric resistivity of the relevant metallic component of the laminate. Element $i$ of the laminate also represented $1 / n$ portion of the 
total resistance of the total conductor length. For this reason, the resulting final resistance was equal to the parallel combination of resistances of the individual metallic components. The final relation applicable for the calculation of specific electric resistivity of the laminated conductor was then depicted via Equation (5),

$$
\frac{1}{\rho_{\text {lam }}}=\left(\frac{A_{A l}}{\rho_{A l}}+\frac{A_{C u}}{\rho_{C u}}\right) \cdot \frac{1}{A_{l a m}}
$$

where $\rho$ is the specific electric resistivity $(\Omega \mathrm{m}), A$ is the area $\left(\mathrm{m}^{2}\right), C u$ and $A l$ are indices to characterize the individual component metals, and lam is the index to characterize the laminated rod.

\section{Results}

\section{1. (Sub)structure Development}

Substructure developments within peripheries of the $\mathrm{Cu}$ lamellas of all the swaged (and heat treated) laminated rods were observed in detail via TEM. Swaging down to the diameter of $15 \mathrm{~mm}$ imparted the accumulation of structural defects and substructure formation. Accumulated dislocations forming dislocation cells within the swaged laminate are depicted in Figure 5a, while Figure 5b shows, in detail, evident deformations of grains (horizontal elongation, i.e., elongation in the axial direction of the laminate, imparted by the effect of axial component of the swaging force) and the formation of subgrains within. Heat treatment via regime HT1 did not impart substantial restoration, as the structure still contained a high density of dislocations (Figure $5 \mathrm{c}$ depicts the interior of grain with accumulated dislocations). However, some grains already exhibited a decrease in dislocation density and the tendency to recover (Figure 5d). Finally, the HT2 heat treatment imparted the structure recovery and annihilation of dislocations; the HT2-treated laminate still contained deformed grains, but also dislocation-free grains. Figure 5 e depicts both the mentioned structural features and also documents the presence of the bimodal structure distribution within the HT2-treated rod. The HT2 treatment also introduced the formation of twins. Figure $5 \mathrm{f}$ shows the detail of a restored grain featuring an annealing twin, of which the diffraction pattern is then shown in Figure $5 \mathrm{~g}$.

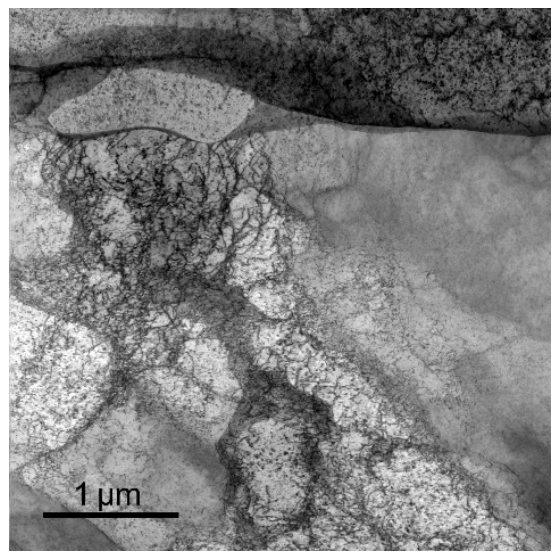

(a)

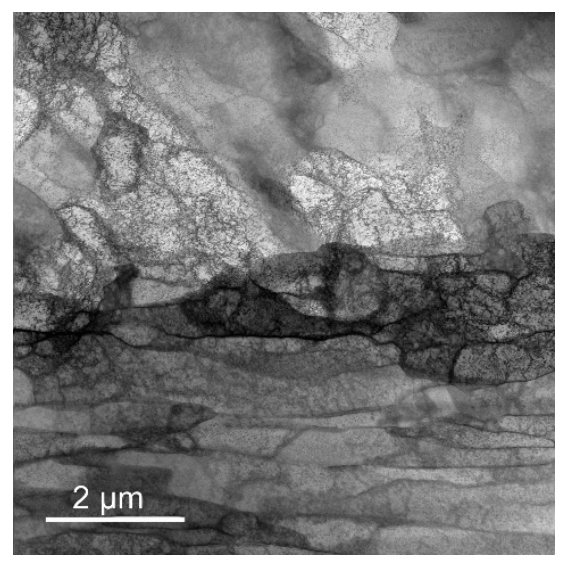

(b)

Figure 5. Cont. 


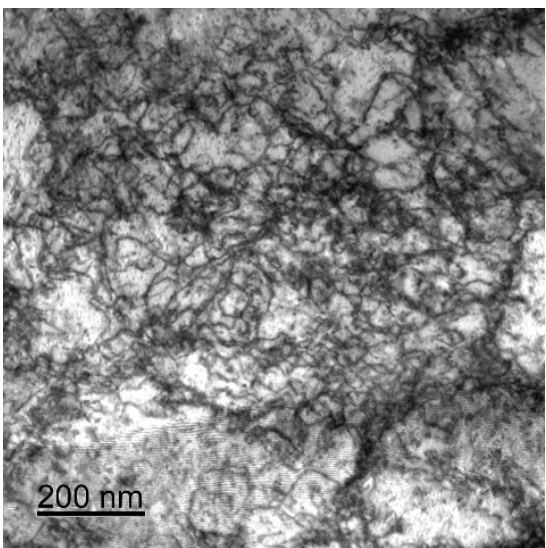

(c)

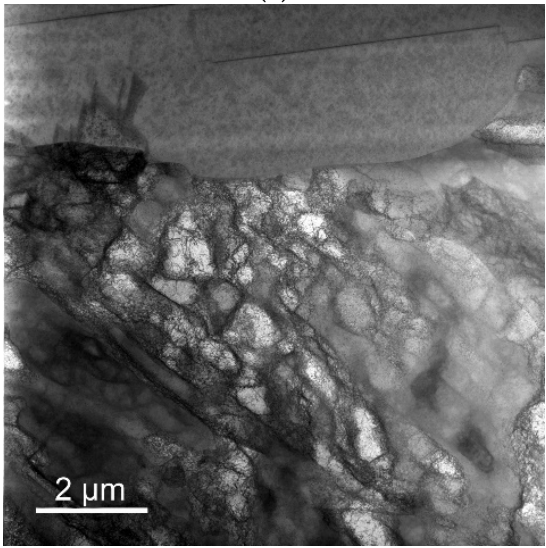

(e)

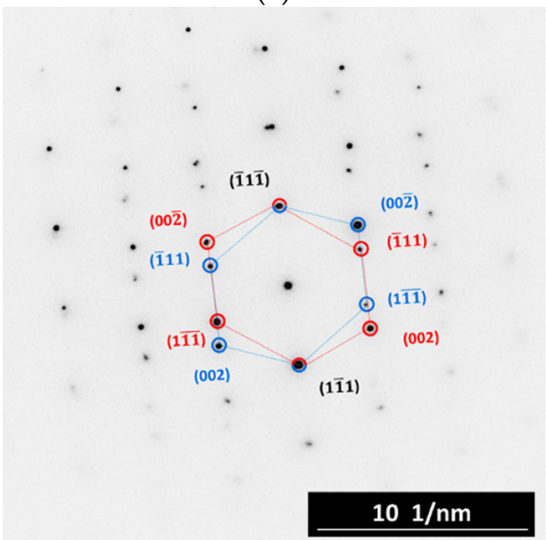

$(\mathrm{g})$

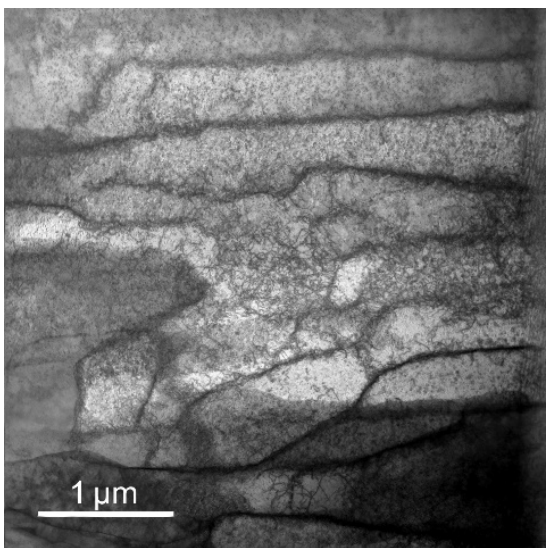

(d)

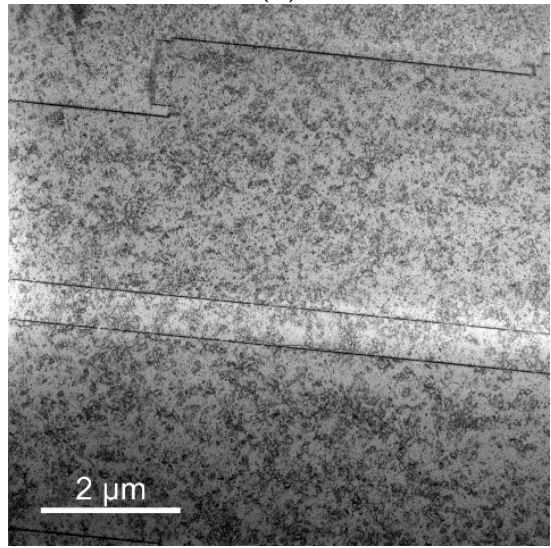

$(\mathbf{f})$

Figure 5. TEM images depicting characteristic structural features for $\mathrm{Cu}$ lamellas of swaged laminate $(\mathbf{a}, \mathbf{b})$; HT1 laminate (c,d); HT2 laminate (e). Twin within structure of HT2 laminate (f) and its diffraction pattern $(\mathbf{g})$.

The results shown above of TEM observations supplemented the SEM analyses, which also showed heavily deformed grains within the $\mathrm{Cu}$ lamellas of the swaged laminate featuring the preferential orientations of the $<001>$ and $<111>$ | | swaging direction (SD) (see Figure 6a depicting the orientation image map, OIM, for a $\mathrm{Cu}$ lamella of the swaged rod). Similar results of grains' orientations were acquired for the HT1 laminate (see the OIM in Figure 6b). However, this sample already exhibited a few relatively small, recrystallized grains with random preferential orientations (small, recrystallized grains diverging from the $<001>$ and $<111>$ | | SD preferential orientations can be seen at the boundaries of larger original grains in Figure $6 \mathrm{~b}$ ). The $\mathrm{Cu}$ lamellas of the heat-treated laminate via regime 
HT2 then exhibited an evident presence of recrystallized, randomly oriented grains at the boundaries of the original grains (see Figure $6 c$ ). The HT2 sample also exhibited a bimodal grain size distribution and annealing twins (see Figure 6d depicting a larger area-compared to Figure $5 \mathrm{f}$ - featuring the bimodal grain size distribution and twins).

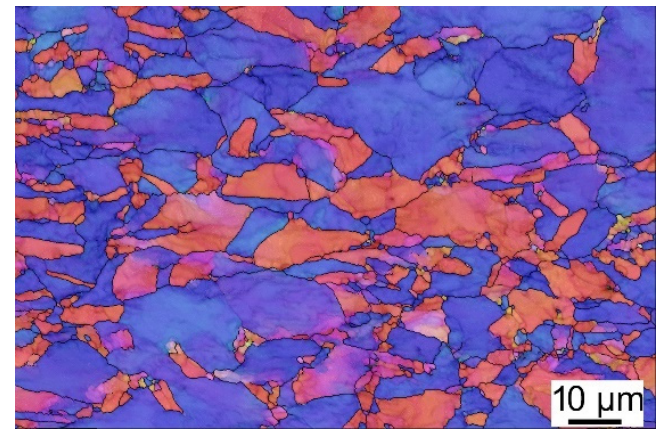

(a)

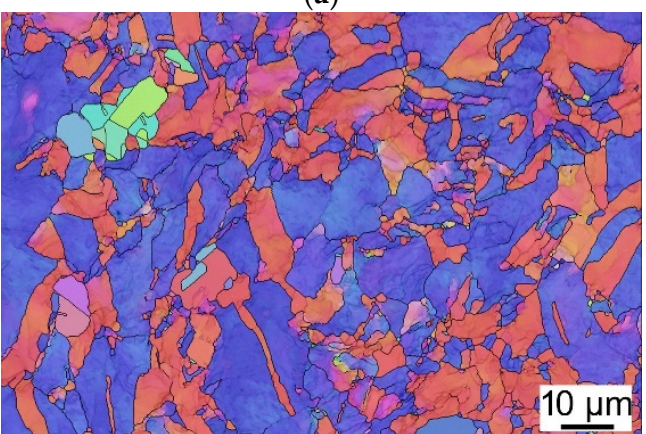

(c)

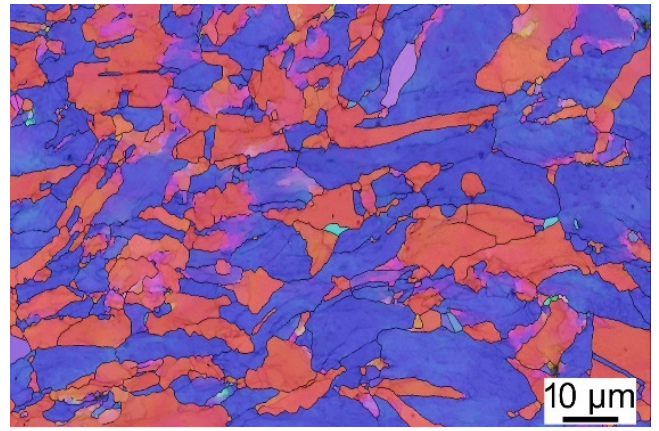

(b)

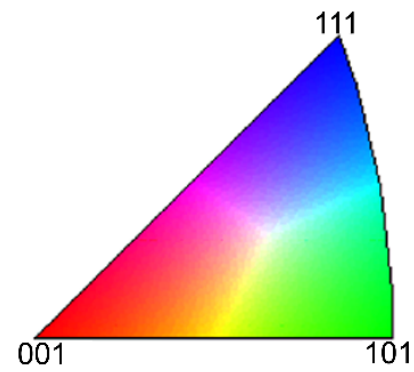

(d)

Figure 6. SEM OIM images for Cu lamellas of swaged laminate (a); HT1 laminate (b); HT2 laminate (c); OIM legend (d).

The SEM OIM images for the Al matrices of the swaged, HT1-, and HT2-laminated rods are depicted in Figure $7 \mathrm{a}-\mathrm{c}$, respectively. Similar to the further discussed grain size analyses (Section 3.2), the analyses of Al grains' orientations did not reveal any significant differences between the individual material states. As the Al matrix most probably exhibited dynamic recrystallization during swaging to the final laminate diameter of $15 \mathrm{~mm}$, all the $\mathrm{Al}$ components within the three examined laminates exhibited more or less equiaxed fine grains featuring comparable portions of the $<001>$ | | SD and $<111>$ | | SD preferential orientations. The portion of randomly oriented recrystallized grains within the $\mathrm{Al}$ components were generally higher than within the $\mathrm{Cu}$ components for all the investigated swaged (and heat treated) laminates.

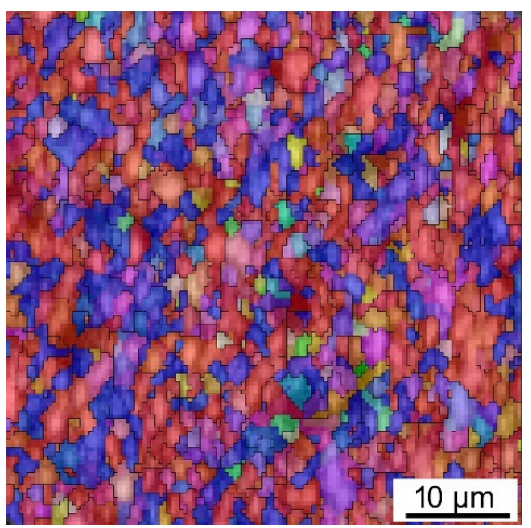

(a)

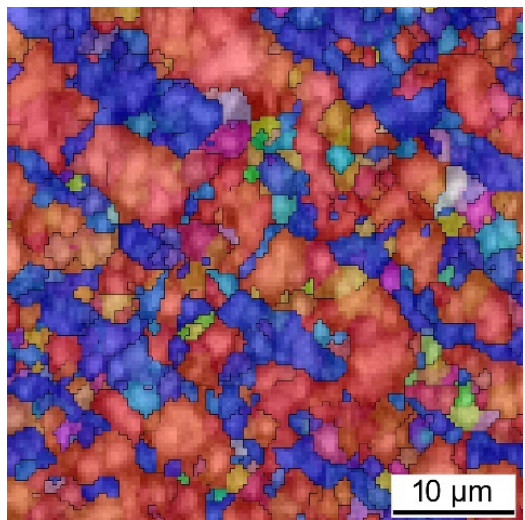

(b)

Figure 7. Cont. 


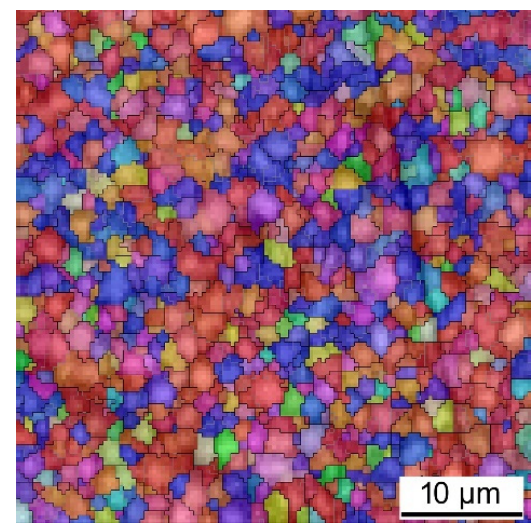

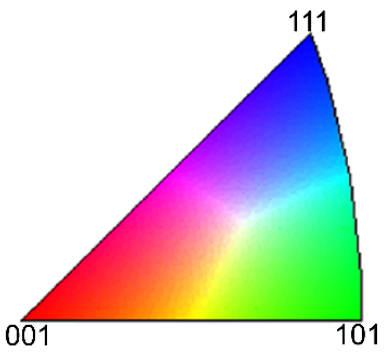

(d)

(c)

Figure 7. SEM OIM images for Al matrix of swaged laminate (a); HT1 laminate (b); HT2 laminate (c); OIM legend $(\mathbf{d})$.

\subsection{Grain Size}

The effects of the intensive plastic deformation on grain sizes of the components of the laminate were assessed, too. The grain sizes were evaluated using the maximum Feret diameter parameter, which is defined as the largest distance between two points defining an individual grain [36]. The average grain sizes for the components of the laminated rods were calculated from the overall numbers of grains present at the respective scanned regions. The graphical depictions of grain sizes were presented as the area-weighted fraction distributions, which depict sums of areas occupied by the grains with the respective diameter, i.e., total areas occupied by the grains at the scanned region, instead of the total number of grains with the respective size [37].

The average grain sizes (in $\mu \mathrm{m}$ ) for the original $\mathrm{Cu}$ and $\mathrm{Al}$ were $36.9 \mu \mathrm{m}$ and $64.0 \mu \mathrm{m}$, respectively. The average grain sizes within the swaged laminate were $3.1 \mu \mathrm{m}$ for the $\mathrm{Cu}$ and $3.0 \mu \mathrm{m}$ for the $\mathrm{Al}$ components. The $H T 1$ treatment imparted grain growth (especially for the $\mathrm{Cu}$ components), as the average grain sizes for the $\mathrm{HT1}$ laminate were $4.8 \mu \mathrm{m}$ for $\mathrm{Cu}$ and $3.2 \mu \mathrm{m}$ for Al components. Compared to the swaged state, the standard deviations from the average grain sizes also increased for both the metals, which confirmed the presence of a bimodal grain size distribution (as documented also in Section 3.1). Finally, the HT2 treatment resulted in a slight decrease in the average grain sizes, as their values for the HT2 laminate decreased to $4.2 \mu \mathrm{m}$ for the $\mathrm{Cu}$ and $2.8 \mu \mathrm{m}$ for the $\mathrm{Al}$ components. This fact could be attributed to the abovementioned increased fractions of small, recrystallized grains for this laminate; also, the standard deviations decreased again compared to the HT1 laminate.

The grain size distributions for the original $\mathrm{CP} C \mathrm{Cu}$ and $\mathrm{CP} \mathrm{Al}$ are depicted in Figure 8a,b, respectively. For the laminates, the analyses were performed at the peripheries of the swaged (and heat treated) rods, since the effect of the deformation processing was the highest in these regions [38]. Figure 8c,d depicts the area-weighted grain size distributions for the $\mathrm{Cu}$ lamella and $\mathrm{Al}$ matrix, respectively, of the swaged laminated rod. Figure 8e,f then shows the area-weighted grain size distributions for the $\mathrm{Cu}$ lamella and $\mathrm{Al}$ matrix, respectively, of the swaged laminated rod heat treated via regime HT1. Finally, Figure 8g,h depicts the area-weighted grain size distributions for the $\mathrm{Cu}$ lamella and $\mathrm{Al}$ matrix, respectively, of the swaged laminated rod heat treated via regime HT2. 


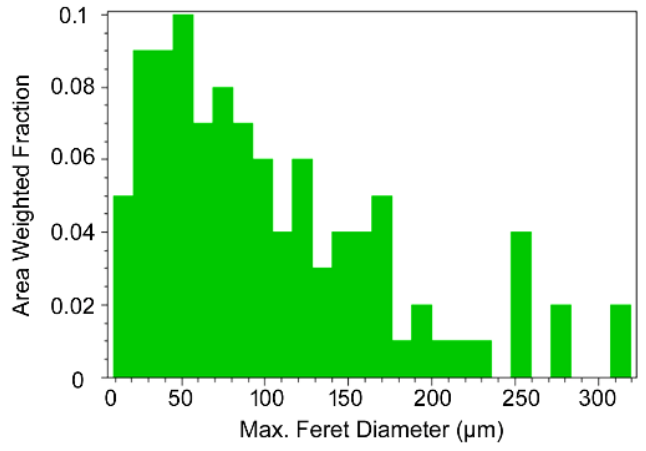

(a)

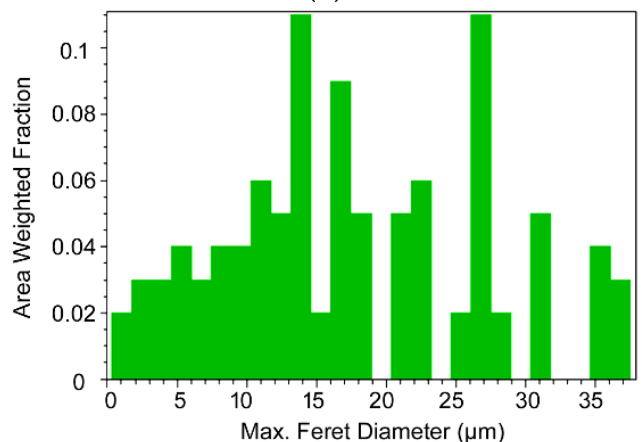

(c)

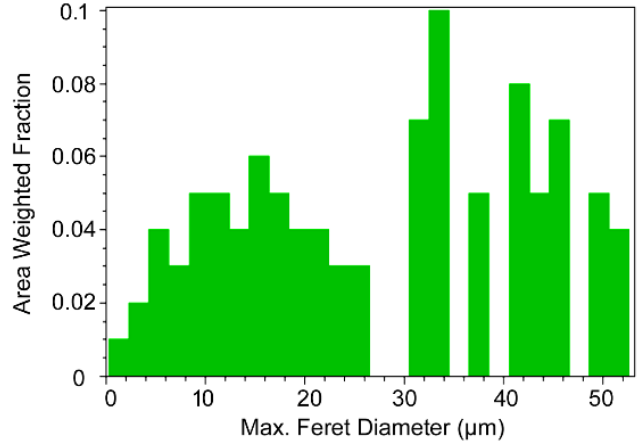

(e)

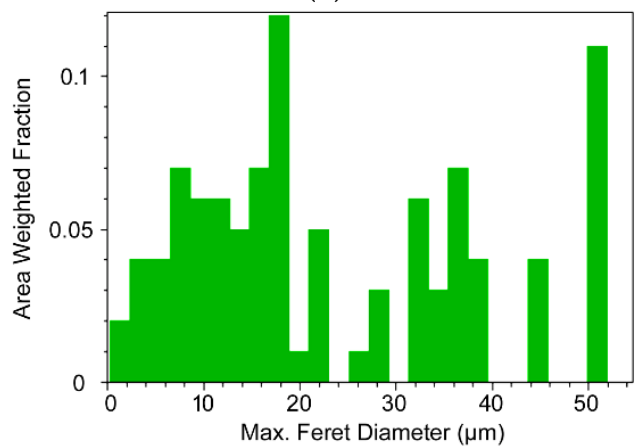

(g)

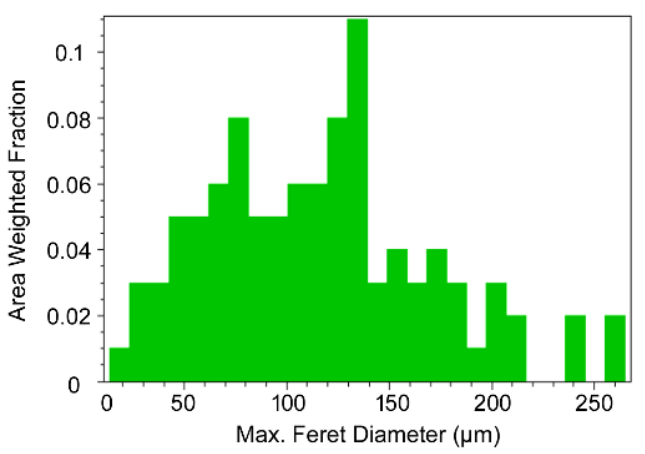

(b)

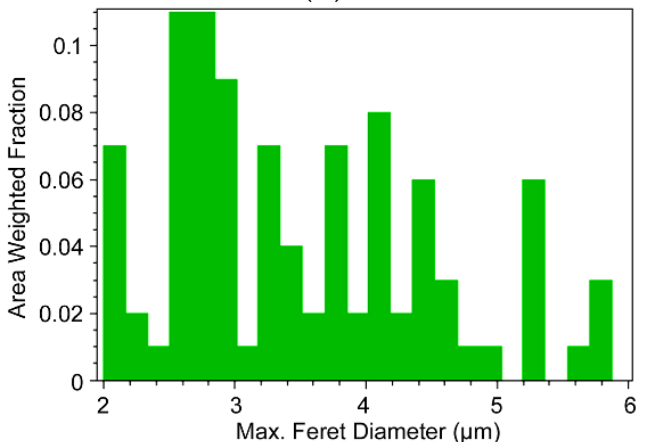

(d)

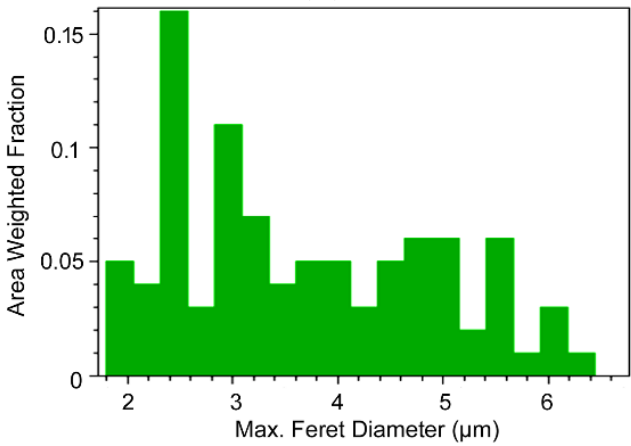

(f)

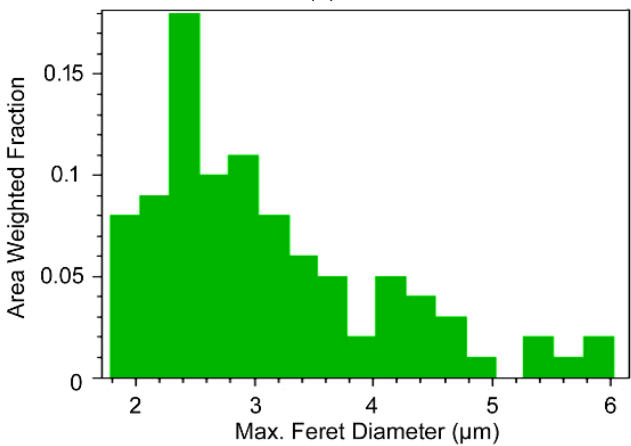

(h)

Figure 8. Grain size distributions for original metals: $\mathrm{CP} \mathrm{Cu}(\mathbf{a}), \mathrm{CP} \mathrm{Al}(\mathbf{b})$. Grain size distributions for swaged laminate: $\mathrm{Cu}$ lamella (c), Al matrix (d); HT1 laminate: Cu lamella (e), Al matrix (f); HT2 laminate: Cu lamella (g), Al matrix (h).

\subsection{Microhardness}

As evident from Figure 9, the highest Vickers microhardness value of $115 \mathrm{HV}$ was measured for the $\mathrm{Cu}$ lamellas of the swaged laminated rod. The microhardness of the $\mathrm{Cu}$ lamellas then decreased as a result of the effect of structure softening introduced by the post-process heat treatments; the lowest average microhardness value measured for 
$\mathrm{Cu}$ lamellas $(76.5 \mathrm{HV})$ was detected for the lamellas of the HT2 rod. As regards the Al matrices, the differences between the microhardness values of the individual laminated rods were not as significant as for the $\mathrm{Cu}$ lamellas as the $\mathrm{Al}$ exhibited more significant dynamic recrystallization during swaging (documented in Section 3.1). The average HV values for the $\mathrm{Al}$ components of the swaged and HT1 rods were comparable (41 HV and $40.3 \mathrm{HV}$, respectively). The HV value then slightly decreased to $32.3 \mathrm{HV}$ for the $\mathrm{Al}$ matrix of the HT2 rod.

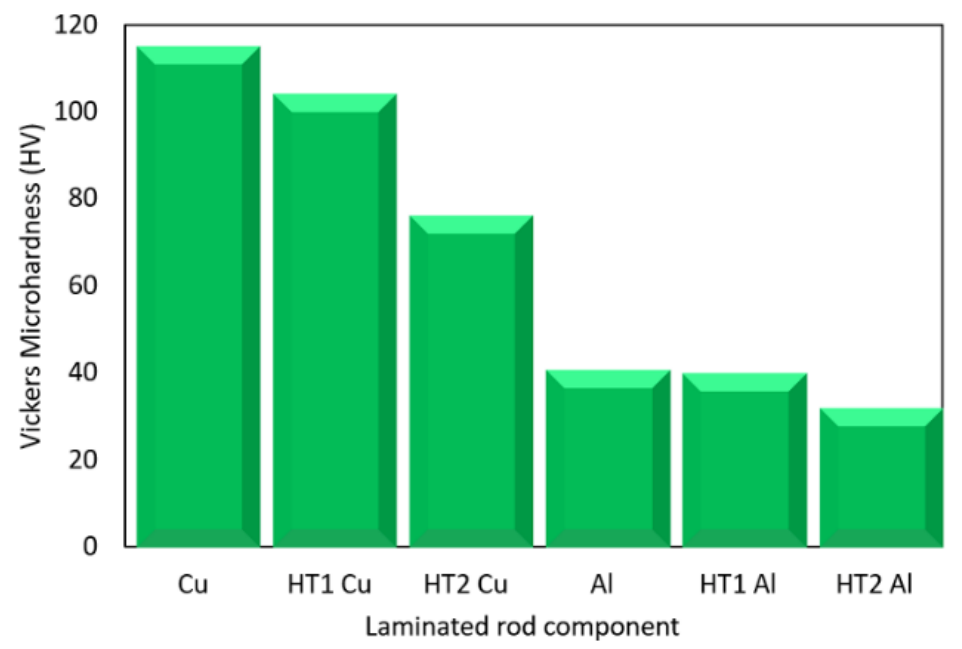

Figure 9. Measured Vickers microhardness values for laminates' components.

\subsection{Electric Properties}

As regards the electric characteristics of the swaged (and heat treated) laminates, the results of the numerical simulations were evaluated at first. The basic output of the harmonic analysis was the distribution of current density across the cross-sections of the swaged laminates, which is depicted in Figure 10 for the laminates swaged to the diameters of $20 \mathrm{~mm}, 15 \mathrm{~mm}$, and $10 \mathrm{~mm}$ (the geometrical layout of the individual metallic components across the laminates' cross-sections corresponded to the real geometries of the laminates observed by SEM). As evident from the figure, the current density was distributed homogeneously across the cross-sectional areas of all the examined laminates. Higher current density values were observed in the axial $\mathrm{Cu}$ cores, as well as in the peripheral $\mathrm{Cu}$ lamellas. In other words, generally lower current density values were observed for the $\mathrm{Al}$ matrices, whereas higher values were observed for the $\mathrm{Cu}$ lamellas.

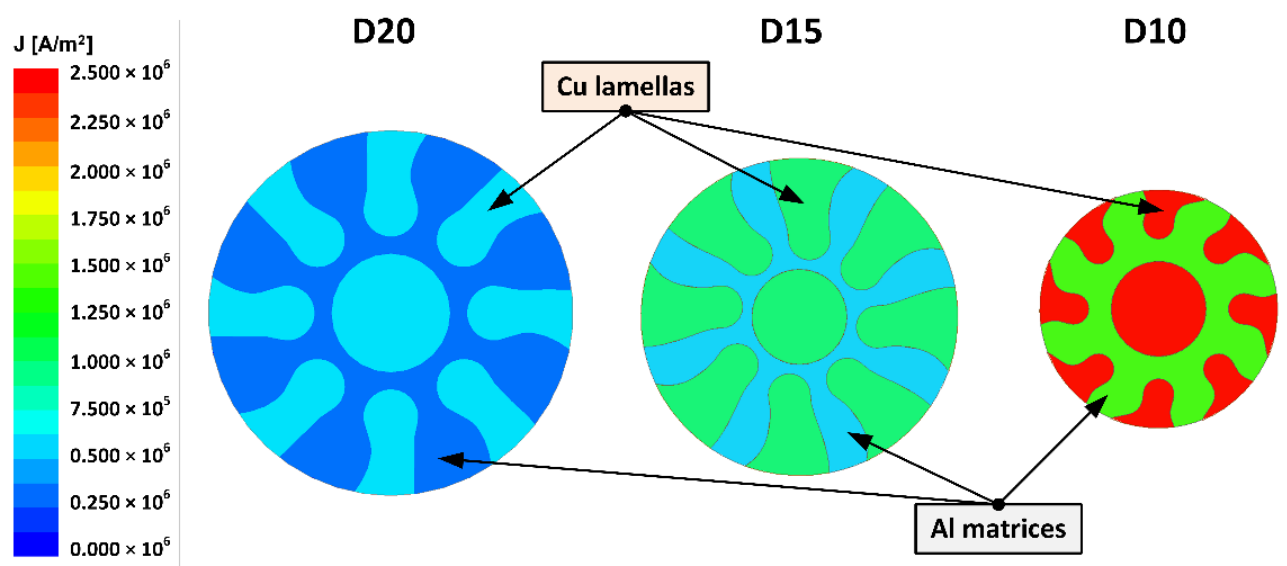

Figure 10. Numerically simulated distribution of current density across cross-sections of laminates swaged to $20 \mathrm{~mm}, 15 \mathrm{~mm}$, and $10 \mathrm{~mm}$ (cross-sectional layouts of $\mathrm{Al}$ and $\mathrm{Cu}$ components based on geometries observed by SEM scanning of cross-sections of experimentally swaged laminates). 
The methods by which the electric characteristics of the laminates were further experimentally measured and calculated were described in Section 2, in which the results of measurements of electric resistivity for the CP metals were also depicted. Expressed in numbers, the specific resistivity and resistance, respectively, were $17.468 \Omega \mathrm{m} \times 10^{-9}$ and $225.1 \Omega \times 10^{-6}$ for $\mathrm{Cu}$, and $28.772 \Omega \mathrm{m} \times 10^{-9}$ and $441.3 \Omega \times 10^{-6}$ for Al. During evaluations of the electric properties of the laminates, these values of the original metals were considered.

Figure 11 depicts the dependence of the voltage drop $V_{1}$ on the applied electric current for the swaged (and heat treated) laminated rods. Similar to the original CP metals, the data for the laminates were smoothed by linear fits. The figure thus depicts that the values of the voltage drop exhibited a linear increase with increasing electric current applied for all the examined material states. The slopes of the curves again characterized the resistances $R$ of the laminated rods. As can be seen from the figure, the resistances of the swaged laminate and laminate heat treated via regime HT2 were comparable. However, the laminate heat treated via regime $H T 1$ exhibited significantly increased resistance. To enable a comparison of resistances of the produced laminates, Figure 11 also includes the curves acquired experimentally for $\mathrm{CP}$ $\mathrm{Al}$ and $\mathrm{CP} \mathrm{Cu}$ rods, i.e., rods of the original metallic components swaged to a diameter of $15 \mathrm{~mm}$. Evidently, the electric conductivity of the swaged laminate was superior to that of $\mathrm{CP}$ Al but deteriorated when compared to $\mathrm{CP} \mathrm{Cu}$. Similar results were also acquired for the HT2 laminate. The HT1 laminate exhibited deteriorated electric conductivity when compared to both the original metals in swaged states.

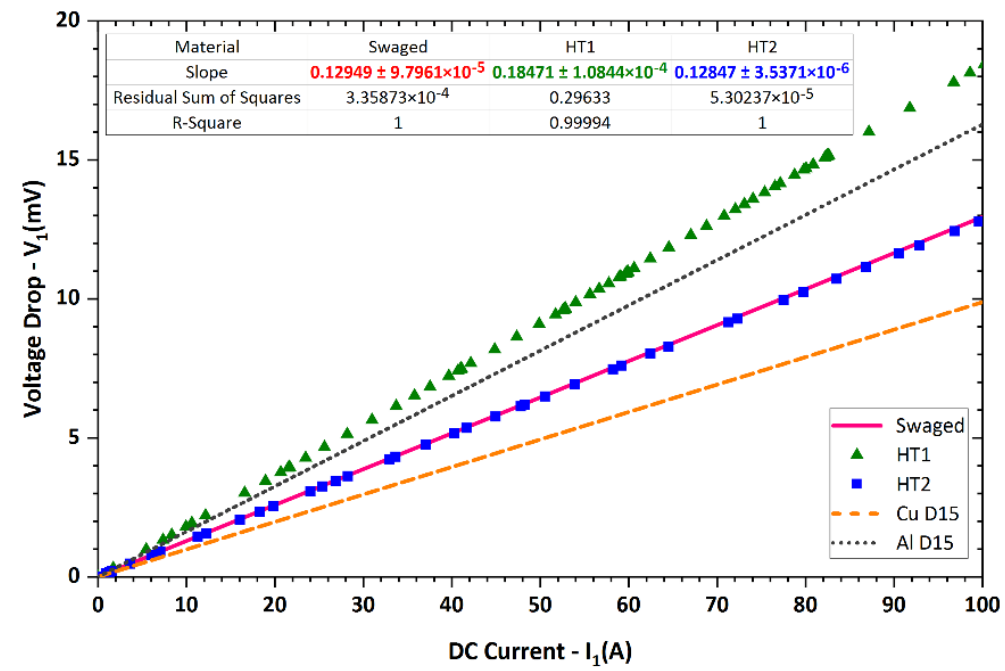

Figure 11. Experimentally acquired dependences of voltage drop on applied direct current for swaged and heat-treated laminates and for swaged original metals.

\section{Discussion}

The assembled laminated semi-products with an original diameter of $50 \mathrm{~mm}$ were gradually swaged to laminated rods with a diameter of $15 \mathrm{~mm}$, which not only affected the structures of the laminates, but also their electric properties. Swaging with a total reduction ratio of 2.4 resulted in deformation strengthening and significant grain refinement, pointing to the occurrence of dynamic recrystallization during processing.

Generally, the grains within the $\mathrm{Cu}$ lamellas were larger than the grains within the Al matrices for all the swaged and heat-treated laminated rods. The primary reason for this phenomenon was that deformation strengthening was processed differently within the metallic components, which was given by the differences in their intrinsic properties and lattice parameters (the Al matrix tended to consume the imposed shear strain more easily than $\mathrm{Cu}$ ) [31]. The $\mathrm{Al}$ matrices exhibited higher portions of recrystallized grains featuring more randomized orientations than the $\mathrm{Cu}$ lamellas. This fact, together with the abovementioned grain size results, points to the significant occurrence of dynamic 
recrystallization within the $\mathrm{Al}$ matrix during swaging. The energy imparted by the HT1 treatment performed at $250{ }^{\circ} \mathrm{C}$ introduced the slight growth of the grains, rather than further recrystallization. This fact was also confirmed by the grain size measurements, as the average grain sizes of both the $\mathrm{Al}$ and $\mathrm{Cu}$ components increased slightly after the HT1 treatment (compared to the swaged laminate). Nevertheless, increasing the annealing temperature to $350{ }^{\circ} \mathrm{C}$ imparted sufficient energy for the grains to exhibit the annihilation of dislocations (confirmed by TEM) and partial recrystallization, which was proven not only by the grain size analyses, but also by the presence of fine grains featuring randomized orientations (i.e., deviating from the $<001>$ | | SD and $<111>$ | | SD preferential orientations) within the Al matrix and $\mathrm{Cu}$ lamellas of the HT2-laminated rod.

The observed grain size changes were non-negligibly connected to the substructure development and changes in microhardness of the metallic components, as these phenomena were introduced by the imposed shear strain, i.e., deformation strengthening. Compared to the swaged state, microhardness decreased for the HT2 laminate, especially due to the observed decrease in dislocation density, which resulted in structure softening. The structural phenomena occurring also introduced changes in the geometrical distribution of the metallic components across the cross-section of the laminated rod. As documented by the results of numerical simulations, the current density, as well as the consequent electric characteristics of the laminate, were not only affected by the area fractions of the metallic components across the cross-section of the laminate, but also by the electric conductivities of both the metallic components. The material featuring a lower electric resistivity, i.e., higher conductivity, had a higher tendency to transfer the electric current despite the fact that its cross-sectional area fraction across the transversal cut through the laminate was lower. The higher current density of the respective metallic component caused the electric current to flow primarily through that part of the laminated conductor featuring a lower value of specific electric resistivity. Moreover, from the viewpoint of the transfer of electric current through the laminated conductor, it was not important whether the lengths of the individual material components were mutually insulated, or closely connected, or whether they exhibited certain transitional resistance.

Figure 11 characterizing the experimentally observed electric behaviours of the laminated rods showed that all the swaged and heat-treated laminates exhibited deteriorated electric conductivity when compared to a swaged $\mathrm{Cu}$ rod. This fact was related to the above-discussed structural phenomena, i.e., to deformation strengthening of both the metallic components ensuing from grain size decrease, substructure development, and increase in dislocation density introduced by the intensive plastic deformation [39]. Interestingly, the values of voltage drop $V_{1}$ measured for the commercially available electro-conductive $\mathrm{CP} \mathrm{Cu}$ and CP Al components were different than those calculated for swaged CP Cu and $\mathrm{CP}$ Al rods (linearly increasing trend was considered). In other words, the $V_{1}$ value at the maximum current of $100 \mathrm{~A}$ was $V_{1}=44 \mathrm{mV}$ for $\mathrm{Al}$ and $V_{1}=22 \mathrm{mV}$ for $\mathrm{Cu}$ (see Figure 2). Nevertheless, for rods swaged to the diameter of $15 \mathrm{~mm}$, the theoretically calculated $V_{1}$ values are $V_{1}=26.5 \mathrm{mV}$ for $\mathrm{CP} \mathrm{Al}$ and $V_{1}=14.6 \mathrm{mV}$ for $\mathrm{CP} \mathrm{Cu}$. However, the real values measured for the $15 \mathrm{~mm}$ rods swaged within this study were $V_{1}=16 \mathrm{mV}$ for CP Al and $V_{1}=10 \mathrm{mV}$ for CP Cu (see Figure 11). This fact confirmed that swaging imparted significant positive changes in the microstructures of both the metallic components (compared to original annealed CP states). The imposed strain imparting the substructure development thus favourably affected electric conductivity, i.e., resulted in an electric resistivity decrease. Generally, the presence of annealing twins, which is typically significant in rolled/drawn and annealed $\mathrm{Cu}$ pieces, contributes to an electric resistivity increase [39]. This was most likely the primary reason for the higher resistivity of the original annealed $\mathrm{CP} \mathrm{Cu}$ (compared to the swaged CP Cu rod). On the other hand, the larger grain size, which is typically observed within annealed non-deformed metals, contributes to higher electric conductivity given by the relatively low volume of grain boundaries, which act as barriers during the electric current transfer (similar to other structural features, which can possibly be present in deformed structures, such as dislocation cells and subgrains). 
Partial structure restoration, i.e., the presence of small, recrystallized grains with randomized preferential orientations within the structure (primarily the Al matrix), imparted an increase in the electric resistivity. In other words, partial reorientations of subgrains, i.e., grains defined by low-angle grain boundaries newly developing within the original grains [40], introduced by the heat treatment at the lower temperature (HT1) resulted in increased electric resistivity compared to the swaged material state. On the contrary, heat treatment at the higher temperature (HT2) imparted the annihilation of dislocations, the development of twins, and a relatively large fraction of recrystallized grains featuring randomized orientations. These phenomena again resulted in decreased electric resistivity-its value for the HT2 laminate was comparable to that of the swaged laminate. In summary, structural phenomena, such as deformation twins, can decrease electric conductivity (particularly for pure metals). However, their presence in deformed laminates is not as significant from the viewpoint of increasing electric resistivity. On the other hand, heterogeneity in the orientations of (sub)grains can be a much more substantial factor influencing the electric conductivity of the laminate.

\section{Conclusions}

This paper aimed to characterize the electric properties and structural features of $\mathrm{Al} / \mathrm{Cu}$-laminated rods, which were successfully prepared via combinations of roomtemperature rotary swaging and post-process heat treatments. The assembled composites $50 \mathrm{~mm}$ in diameter were progressively swaged down to laminated rods with a diameter of $15 \mathrm{~mm}$, and subsequently subjected to two heat treatment regimes $\left(250^{\circ} \mathrm{C}=H T 1\right.$, and $\left.350{ }^{\circ} \mathrm{C}=H T 2\right)$. The main acquired results were the following:

- Swaging to the diameter of $15 \mathrm{~mm}$ imparted favourable electric characteristics and an increase in microhardness up to $115 \mathrm{HV}$ for the $\mathrm{Cu}$ components of the laminate.

- HT1 material state - the occurrence of relatively small, restored grains with randomized preferential orientations was the main reason for the observed deterioration of electric conductivity (specific electric resistivity of approx. $34 \times 10^{-9} \Omega \mathrm{m}$ compared to approximately $23.5 \times 10^{-9} \Omega \mathrm{m}$ for the swaged state).

- HT2 material state - the electric conductivity improved to a level comparable with the swaged state (approximately $22.7 \times 10^{-9} \Omega \mathrm{m}$ ); in addition, the higher annealing temperature caused bimodal grain size distribution and the development of annealing twins.

- A favourable effect of rotary swaging on the electric conductivity was also observed for the original $\mathrm{Al}$ and $\mathrm{Cu}$ (theoretically calculated voltage drop values were higher than experimentally measured for both) — this phenomenon was related to substructure development (substantial grain refinement and high dislocation density) imparted by swaging.

The presented results proved that the $\mathrm{Al} / \mathrm{Cu}$ laminate of the proposed stacking sequence is suitable for the production of conductors for direct current transfer. Although there are differences between the characteristics of alternate and direct currents (primarily the occurrence of the skin effect during alternate current transfer), the $\mathrm{Al} / \mathrm{Cu}$ laminate is supposed to also be suitable for alternate current transfer; the detailed investigation of the behaviour of the $\mathrm{Al} / \mathrm{Cu}$ laminate during alternate current transfer is the primary focus of our ongoing research.

Author Contributions: Conceptualization, L.K., P.K., R.K. and M.J.; methodology, L.K., P.K., R.K. and M.J.; experimental validation, L.K., P.K., M.J., R.K. and M.M.; microscopy investigation and evaluation, L.K. and M.J.; mechanical testing and evaluation, M.M. and R.K.; numerical simulations and their evaluation, P.K.; writing-original draft preparation, L.K., R.K.; writing-review and editing, L.K., R.K. and M.J.; project administration, L.K. and R.K.; funding acquisition, L.K. and R.K. All authors have read and agreed to the published version of the manuscript.

Funding: The authors give thanks for the support of Project 19-15479S of the Grant Agency of the Czech Republic. 


\section{Institutional Review Board Statement: Not applicable.}

Informed Consent Statement: Not applicable.

Data Availability Statement: The original data supporting the research are not publicly available but the data that are not confidential are available on request from the corresponding author.

Acknowledgments: We acknowledge the help of the IPMinfra research infrastructure of the Institute of Physics of Materials, CAS.

Conflicts of Interest: The authors declare no conflict of interest. The funders had no role in the design of the study, in the collection, analyses, or interpretation of data, in the writing of the manuscript, or in the decision to publish the results.

\section{References}

1. Velmurugan, C.; Subramanian, R.; Thirugnanam, S.; Anandavel, B. Investigation of friction and wear behavior of hybrid aluminium composites. Ind. Lubr. Tribol. 2012, 64, 152-163. [CrossRef]

2. Rajesh, A.M.; Kaleemulla, M. Experimental investigations on mechanical behavior of aluminium metal matrix composites. IOP Conf. Ser. Mater. Sci. Eng. 2016, 149, 012121. [CrossRef]

3. Mendes, R.; Ribeiro, J.B.; Loureiro, A. Effect of explosive characteristics on the explosive welding of stainless steel to carbon steel in cylindrical configuration. Mater. Des. 2013, 51, 182-192. [CrossRef]

4. Jamili, A.M.; Zarei-Hanzaki, A.; Abedi, H.R.; Mosayebi, M.; Kocich, R.; Kunčická, L. Development of fresh and fully recrystallized microstructures through friction stir processing of a rare earth bearing magnesium alloy. Mater. Sci. Eng. A 2019, 775, 138837. [CrossRef]

5. $\quad$ Shen, W.; Yu, L.; Liu, H.; He, Y.; Zhou, Z.; Zhang, Q. Diffusion welding of powder metallurgy high speed steel by spark plasma sintering. J. Mater. Process. Technol. 2020, 275, 116383. [CrossRef]

6. Kunčická, L.; Král, P.; Dvořák, J.; Kocich, R. Texture evolution in biocompatible Mg-Y-Re alloy after friction stir processing. Metals 2019, 9, 1181. [CrossRef]

7. Montufar, E.B.; Horynová, M.; Casas-Luna, M.; Diaz-de-la-Torre, S.; Celko, L.; Klakurková, L.; Spotz, Z.; Diéguez-Trejo, G.; Fohlerová, Z.; Dvořák, K.; et al. Spark Plasma Sintering of Load-Bearing Iron-Carbon Nanotube-Tricalcium Phosphate CerMets for Orthopaedic Applications. JOM 2016, 684, 1134-1142. [CrossRef]

8. Lukac, P.; Kocich, R.; Greger, M.; Padalka, O.; Szaraz, Z. Microstructure of AZ31 and AZ61 Mg alloys prepared by rolling and ECAP. Kov. Mater. 2007, 45, 115-120.

9. Hlaváč, L.M.; Kocich, R.; Gembalová, L.; Jonšta, P.; Hlaváčová, I.M. AWJ cutting of copper processed by ECAP. Int. J. Adv. Manuf. Technol. 2016, 86, 885-894. [CrossRef]

10. Kocich, R.; Szurman, I.; Kursa, M.; Fiala, J. Investigation of influence of preparation and heat treatment on deformation behaviour of the alloy NiTi after ECAE. Mater. Sci. Eng. A 2009, 512, 100-104. [CrossRef]

11. Kunčická, L.; Kocich, R.; Ryukhtin, V.; Cullen, J.C.T.; Lavery, N.P. Study of structure of naturally aged aluminium after twist channel angular pressing. Mater. Charact. 2019, 152, 94-100. [CrossRef]

12. Kocich, R.; Kunčická, L.; Macháčková, A. Twist Channel Multi-Angular Pressing (TCMAP) as a method for increasing the efficiency of SPD. IOP Conf. Ser. Mater. Sci. Eng. 2014, 63, 012006. [CrossRef]

13. Derakhshan, J.F.; Parsa, M.H.; Jafarian, H.R. Microstructure and mechanical properties variations of pure aluminum subjected to one pass of ECAP-Conform process. Mater. Sci. Eng. A 2019, 747, 120-129. [CrossRef]

14. Kunčická, L.; Kocich, R.; Drápala, J.; Andreyachshenko, V.A. FEM simulations and comparison of the ecap and ECAP-PBP influence on Ti6Al4V alloy's deformation behaviour. Proc. Met. 2013, 22, 391-396.

15. Kunčická, L.; Kocich, R. Deformation behaviour of Cu-Al clad composites produced by rotary swaging. IOP Conf. Ser. Mater. Sci. Eng. 2018, 369, 012029. [CrossRef]

16. Kunčická, L.; Kocich, R.; Strunz, P.; Macháčková, A. Texture and residual stress within rotary swaged Cu/Al clad composites. Mater. Lett. 2018, 230, 88-91. [CrossRef]

17. Zach, L.; Kunčická, L.; Růžička, P.; Kocich, R. Design, analysis and verification of a knee joint oncological prosthesis finite element model. Comput. Biol. Med. 2014, 54, 53-60. [CrossRef]

18. Lee, K.S.; Lee, S.E.; Sung, H.K.; Lee, D.H.; Kim, J.S.; Chang, Y.W.; Lee, S.; Kwon, Y.N. Influence of reduction ratio on the interface microstructure and mechanical properties of roll-bonded Al/Cu sheets. Mater. Sci. Eng. A 2013, 583, 177-181. [CrossRef]

19. Cawthorn, C.J.; Minton, J.J.; Brambley, E.J. Asymptotic analysis of cold sandwich rolling. Int. J. Mech. Sci. 2016, 106, 184-193. [CrossRef]

20. Torres-Rodríguez, J.; Kalmár, J.; Menelaou, M.; Čelko, L.; Dvořak, K.; Cihlář, J.; Cihlař, J.; Kaiser, J.; Győri, E.; Veres, P.; et al. Heat treatment induced phase transformations in zirconia and yttria-stabilized zirconia monolithic aerogels. J. Supercrit. Fluids. 2019, 149, 54-63. [CrossRef]

21. Wu, K.; Chang, H.; Maawad, E.; Gan, W.M.; Brokmeier, H.G.; Zheng, M.Y. Microstructure and mechanical properties of the $\mathrm{Mg} / \mathrm{Al}$ laminated composite fabricated by accumulative roll bonding (ARB). Mater. Sci. Eng. A 2010, 527, 3073-3078. [CrossRef] 
22. Mozaffari, A.; Manesh, H.D.; Janghorban, K. Evaluation of mechanical properties and structure of multilayered Al/Ni composites produced by accumulative roll bonding (ARB) process. J. Alloys Compd. 2010, 489, 103-109. [CrossRef]

23. Ghalandari, L.; Mahdavian, M.M.; Reihanian, M.; Mahmoudiniya, M. Production of Al/Sn multilayer composite by accumulative roll bonding (ARB): A study of microstructure and mechanical properties. Mater. Sci. Eng. A 2016, 661, 179-186. [CrossRef]

24. Tayyebi, M.; Eghbali, B. Study on the microstructure and mechanical properties of multilayer Cu/Ni composite processed by accumulative roll bonding. Mater. Sci. Eng. A 2013, 559, 759-764. [CrossRef]

25. Hosseini, M.; Manesh, H.D. Bond strength optimization of Ti/Cu/Ti clad composites produced by roll-bonding. Mater. Des. 2015, 81, 122-132. [CrossRef]

26. Mahdavian, M.M.; Ghalandari, L.; Reihanian, M. Accumulative roll bonding of multilayered Cu/Zn/Al: An evaluation of microstructure and mechanical properties. Mater. Sci. Eng. A Struct. Mater. Prop. Microstruct. Process 2013, 579, 99-107. [CrossRef]

27. Motevalli, P.D.; Eghbali, B. Microstructure and mechanical properties of laminated Al-Cu-Mg composite fabricated by accumulative roll bonding. Bull. Mater. Sci. 2017, 40, 1481-1488. [CrossRef]

28. Kim, I.-K.; Hong, S.I. Roll-Bonded Tri-Layered Mg/Al/Stainless Steel Clad Composites and their Deformation and Fracture Behavior. Metall. Mater. Trans. A 2013, 44, 3890-3900. [CrossRef]

29. Jafarian, H.R.; Mahdavian, M.M.; Shams, S.A.A.; Eivani, A.R. Microstructure analysis and observation of peculiar mechanical properties of $\mathrm{Al} / \mathrm{Cu} / \mathrm{Zn} / \mathrm{Ni}$ multi-layered composite produced by Accumulative-Roll-Bonding (ARB). Mater. Sci. Eng. A 2021, 805, 140556. [CrossRef]

30. Uscinowicz, R. Impact of temperature on shear strength of single lap Al-Cu bimetallic joint. Compos. Part B Eng. 2013, 44, 344-356. [CrossRef]

31. Russell, A.; Lee, K.L. Structure-Property Relations in Nonferrous Metals, 1st ed.; John Wiley \& Sons, Inc.: Hoboken, NJ, USA, 2005.

32. Kocich, R.; Macháčková, A.; Kunčická, L.; Fojtík, F. Fabrication and characterization of cold-swaged multilayered Al-Cu clad composites. Mater. Des. 2015, 71, 36-47. [CrossRef]

33. Kocich, R.; Kunčická, L.; Král, P.; Strunz, P. Characterization of innovative rotary swaged Cu-Al clad composite wire conductors Mater. Des. 2018, 160, 160828-160835. [CrossRef]

34. Kocich, R.; Kunčická, L.; Macháčková, A.; Šofer, M. Improvement of mechanical and electrical properties of rotary swaged Al-Cu clad composites. Mater. Des. 2017, 123, 137-146. [CrossRef]

35. Webster, J.G. Electrical Measurement, Signal Processing, and Displays (Principles and Applications in Engineering), 1st ed.; CRC Press: Boca Raton, FL, USA, 2003.

36. Gennesson, M.; Zollinger, J.; Daloz, D.; Rouat, B.; Demurger, J.; Combeau, H. Three Dimensional Methodology to Characterize Large Dendritic Equiaxed Grains in Industrial Steel Ingots. Materials 2018, 11, 1007. [CrossRef] [PubMed]

37. Toth, L.S.; Biswas, S.; Gu, C.; Beausir, B. Notes on representing grain size distributions obtained by electron backscatter diffraction Mater. Charact. 2013, 84, 67-71. [CrossRef]

38. Kunčická, L.; Kocich, R.; Dvořák, K.; Macháčková, A. Rotary swaged laminated Cu-Al composites: Effect of structure on residual stress and mechanical and electric properties. Mater. Sci. Eng. A 2019, 742, 743-750. [CrossRef]

39. Kocich, R.; Macháčková, A.; Kunčická, L. Twist channel multi-angular pressing (TCMAP) as a new SPD process: Numerical and experimental study. Mater. Sci. Eng. A 2014, 612, 445-455. [CrossRef]

40. Humphreys, F.J.; Hetherly, M. Recrystallization and Related Annealing Phenomena, 2nd ed.; Elsevier Ltd.: Oxford, UK, 2004. 